\title{
FACTORS INFLUENCING PRICES PAID IN THE MARKET FOR TEMPORARY WATER
}

\author{
HENNING BJORNLUND and PETER ROSSINI \\ University of South Australia
}

\begin{abstract}
This paper explores the factors which influence the willingness of irrigators to pay for water in temporary markets. The analyses are based on ten years of data using correlation, regression and time series techniques. The major drivers of price are: (i) water scarcity, as determined by seasonal availability of water; (ii) demand factors, as determined by precipitation and evaporation; and (iii) potential longterm losses incurred by irrigators with significant investments in water dependent infrastructure if insufficient water is used. These irrigators are willing to pay prices in excess of the value of water in productive use in order to protect their production and thereby the value of their assets.
\end{abstract}

Keywords: Water markets, water market drivers, Victoria, Australia.

\section{INTRODUCTION}

Water scarcity is a problem in most countries in the world. As water scarcity intensifies, the water economy is said to be in transit from the expansionary phase to the mature phase. This happened in Australia in the latter part of the 1970s and early part of the1980s. Randall (1981) argues that this transition takes place when the marginal cost of providing new supply is high and the long run supply of water is therefore inelastic, the total demand for water is high and growing, the competition for water among users is intense, and externality problems are pressing. The mature phase therefore saw a shift in policy paradigm away from meeting new demand with new supply towards requiring new demand to be met by a reallocation of existing scarce resources between competing users. This shift in paradigm does not only have implications for agricultural water users and rural property values, but is slowly making its impact within urban areas as well. As cities and townships expand and use all the water they are entitled to, they can only increase their supply by getting water from other existing water users, which in reality means from agricultural users.

Many international organizations and national governments currently place great importance on water markets as the most appropriate policy instrument to facilitate this reallocation of water. At the same time, they seek to promote more efficient and higher valued water use and to provide some financial compensation to selling 
farmers so that the socioeconomic impact within rural communities can be minimized. Both the permanent and temporary water markets play an important role in this process. Permanent markets facilitate transfers of long-term access to water, while temporary markets facilitate transfers of the temporary right to use water (predominantly on a seasonal basis).

Urban water authorities can take two main approaches to ensure that there is sufficient water for urban uses during all years. Firstly, they can buy enough water on the permanent market to ensure sufficient water for the city, even during years of drought and then sell the water back to the rural users during years when it is not needed. Second, they can acquire only enough long-term water entitlements for say $70 \%$ of all years and then buy water on the temporary market during years of drought. It should also be possible for urban users to secure such temporary water through contingent contracts under which an urban water authority makes long-term arrangements with farmers to buy their water under certain climatic conditions or certain supply levels. This contract also determines the price to be paid when the contract comes into effect, and the farm receives a one-off payment when the contract is entered into. This system has operated in the US (Shupe et al., 1989). Reflecting these developments, it is now a condition for granting a development permit, in places such as Mildura in Australia and Phoenix in Arizona, that the developer provides the water authority with the necessary water entitlements to service that development.

Both of these approaches involve the use of the temporary as well as the permanent market; it is therefore important to understand which factors determine the prices that farmers are willing to pay and accept for water, as well as the volume that is traded in the market.

This paper will investigate which factors determine the price that farmers are willing to pay by analyzing the relationship between mean monthly prices and various hypothesized determinants of the willingness of irrigators to pay for water. Ten years of monthly data for prices and potential drivers have been gathered from within the Goulburn Murray Irrigation District (GMID) in Victoria, Australia. These data have been analyzed using correlation, regression and time series techniques to establish the strength of such relationships.

\section{SOME THEORETICAL EXPECTATIONS AND ANECDOTAL OBSERVATIONS}

A search of the international literature does not reveal any other empirical studies of prices of temporary water. Some analyses have been made of prices of permanent water both in the US (Person and Michelsen, 1994; Colby et al., 1993) and in Australia (Bjornlund, 2002a). However, regression analysis have been applied to time series data within the lease market for fishing quotas in the New Zealand 
Fisheries (Kerr et al., 2003). They found that price dispersion within the fisheries quota market was much the same as within markets for other commodities and that the leasing market was far more active than the market for permanent quotas as it has been found for water markets (Bjornlund, 2003a). They also found that prices paid in the lease market reflected economic fundamentals, such as the price of fish, the cost of fishing, demand for quota and the general performance of the economy. The fishing quota market in New Zealand seems to reflect economic fundamentals.

Initial hypotheses therefore largely have to be based on anecdotal evidence and theoretical expectations (Bjornlund, 2003a,b,c). It could on this basis be hypothesized that the willingness to pay for water should be a product of four factors: (i) the profit that can be gained from using the water; this factor should be reflected in the fluctuations in prices for the main commodities produced within the region in which water can be traded; (ii) supply of water; this is measured by the allocation level announced at the beginning of the season and then revised during the season depending on availability of water within the reservoirs supplying the region. The allocation level is announced as the proportion of their entitlements that irrigators can use during that season; (iii) demand for water; this would be influenced by the level of the seasonal allocation and commodity prices as discussed above, but also by the level of natural precipitation and evaporation. Finally, demand for water could be determined by the price of substitute goods within the study region; this is relevant, since dairy farming is one of the high value uses and dairy farmers can substitute the use of water to grow grass by buying feed in the form of hay, feeding grain or silage; and (iv) the potential loss irrigators would suffer if insufficient water is applied during periods of water scarcity. This is an important issue for farmers with permanent plantings, which could be lost, or the yield from which could be negatively affected for several years, if insufficient water is applied; it is also an important issue for dairy farmers with significant investments in dairy herds, milking equipment and permanent pastures.

The following subsections will briefly discuss each of these theoretical factors and provide some anecdotal evidence from within the GMID, based on Bjornlund (2003a,b,c).

\section{Commodity prices}

When commodity prices are high, it could be expected that irrigators are willing to pay a higher price for water and that irrigators will require a higher price in order to be convinced to sell their water. Fundamentally, the differences in value generated per ML of water used within the area should provide the incentive to trade for both buyers and sellers. Within the study region, there is a great diversity in gross margin figures for water in different uses: (i) grazing for cattle or sheep at $\mathrm{A} \$ 50 / \mathrm{ML}$; (ii) grain growing at about $\mathrm{A} \$ 100 / \mathrm{ML}$; (iii) grazing for dairy production at about $\mathrm{A} \$ 500 / \mathrm{ML}$; (iv) various vegetables at $\mathrm{A} \$ 400-1,800 / \mathrm{ML}$; and $(\mathrm{v})$ wine grapes at about A $\$ 2,800 / \mathrm{ML}$ (DNRE, 2001). Research in Canada has shown a similar 
heterogeneity of water values across commodities (Adamovicz and Holbulyk, 1996). The observed trading pattern within the study region reflects these gross margin figures, with grazing and grain growing properties normally supplying the water, while vegetable growers, horticultural growers and dairy farmers make up demand (Bjornlund, 2002c; Bjornlund and McKay, 2000).

Traditionally, the low value producers such as lamb, cattle, wool and grain growers supply the temporary market, while the higher valued producers such as dairy farmers and horticultural growers make up demand. When commodity prices for these low value producers were high during 2001/02, they were reluctant to sell and this was a contributing factor to escalating water prices toward the middle of that season. Likewise, when dairy prices were relatively high towards the end of that season, it was a contributing factor to record high prices (Bjornlund, 2003b,c).

\section{Supply of water and the drive to prevent losses}

When supply is low, competition for water will be high and irrigators with permanent plantings or pastures are likely to be desperate to buy water to protect these long-term investments. These irrigators are therefore not reacting to the potential gain from buying water, but rather to the size of the potential losses, which can be prevented by buying additional water. There is ample anecdotal evidence of this behaviour in the markets within the study region during the last five to six seasons when water allocations have been very low. Horticultural growers have twice set the price at the maximum level (this is equal to the penalty payable for use in excess of allocation, and has twice been revised upward in response to prices in the market reaching that limit). Dairy farmers tend to choose other management options when prices go that high; that is, buying feed or sending stock on agistment in different locations with higher rainfall (Bjornlund, 2003b,c).

\section{Demand for water}

Demand for water has been driven by commodity prices and the level of supply as discussed in the two preceding sections. In this section, other demand factors will be discussed.

The price of substitute goods in the form of feed for dairy cattle has been an important factor in reducing demand in the temporary market. At the beginning of $1998 / 99$, some extension officers in the study region advised dairy farmers that at prices above $\mathrm{A} \$ 90 / \mathrm{ML}$, they were better-off buying feed rather than buying water to grow grass. This placed a ceiling on water prices during the years from 1998/99 to $2000 / 01$. When the production of feed declined and prices increased due to the extended drought during 2001/02 and 2002/03, the comparative cost of water increased sharply and in some instances, supply of feed was non-existing or difficult and uncertain to obtain; this increased dairy farmers' willingness to pay for water. This was a contributing factor to record high prices towards the end of 2001/02 and again during 2002/03 (Bjornlund, 2003b,c). 
During periods with low natural precipitation and/or high evaporation within the study region, the need for irrigation goes up and potentially increases demand in water markets with a resultant increase in the price. There are several examples of this impact in the market. The spring period of 2000/01 was particularly wet, which reduced the need for early irrigation and thereby reduced demand in water markets; the effect was lower prices. Conversely, the spring of 2001/02 was very dry and hot with strong dry winds; as a result, evaporation was very high, and consequently the need for irrigation was up by $13 \%$ to $15 \%$ compared to past years. This contributed strongly to prices rising to very high levels around December (early summer) that year. During that same season, opening autumn rains were late in arriving, which extended the need to irrigate and added to the already very high demand that had resulted from low water allocations and high feed prices (Bjornlund, 2003b,c).

\section{Concluding comments}

The preceding discussions have given some strong theoretical arguments as to which factors to include in a quantitative analysis and have provided some anecdotal evidence of these factors at work in the market. The discussions, however, also indicate that a number of these factors are at play at the same time and will interact. This could suggest that it is likely to be difficult to differentiate these factors when applying quantitative methods. This issue is further complicated by at least two other factors, which have also had an impact on supply and demand for water and thereby on farmers' willingness to pay:

- During the study period, several policy changes have taken place, easing spatial restrictions to trade and changing the ability to trade between different classes of water entitlements. These changes have allowed a more diverse range of irrigators to compete for the same water and have thereby influenced prices in the market (Bjornlund, 2002a).

- Management decisions, made by the Authority managing the study region, have also influenced supply during the last two seasons by announcing the right to upstream trade of 5,000 ML under the substitution rule. During both years, this decision increased supply and resulted in a temporary drop in price until the market had taken up the additional supply.

To complicate matters still further, a number of other policy issues have impeded the operation of the permanent market and have thereby increased the use of the temporary market (Bjornlund, 2002b):

- One issue is associated with taxation issues; temporary transactions represent annual income or cost with a tax implication in the year of transaction. For the buyers, who are generally higher income farmers (Bjornlund, 2002c), the purchase represents a tax deduction, which helps to reduce their tax burden with about $40 \%$ of the price paid for water, while the sellers, who generally have negative or very low farm incomes, pay no or little tax on the proceeds 
from the sale. On the contrary, permanent transactions do not give any tax deduction or depreciation for the buyer, while it might represent a capital gains liability for the seller. Tax policies are therefore likely to increase buyers' willingness to pay for water in the temporary market, and they are likely to make sellers reluctant to use the permanent market.

- A second issue is related to the fact that recent policy initiatives in Australia have generated a high level of policy uncertainty with respect to the future stream of seasonal allocations that will be produced by water entitlements. All catchments within the Murray-Darling Basin are currently going through a planning process during which water will have to be allocated to the environment before the remaining water resources are shared between consumptive users; as a result, irrigators' access to water will be reduced. Consequently, buyers of water entitlements in the permanent market do not know how much water they are likely to get when they pay for one mega litre of water entitlement. This uncertainty has made irrigators reluctant to buy water in the permanent market and has thereby increased the use of the temporary market - again, increasing demand in that market and forcing prices up. This diversity of drivers of price in the temporary markets and the ways in which they interact are likely to place limits on the strength of the quantitative analysis to follow.

\section{EMPIRICAL ANALYSIS OF PRICES PAID}

To test the hypothesized relationships between the drivers of farmers' willingness to pay for water, prices paid for water have been collected from within the GMID over a ten-year period from 1993/94 to 2002/03, together with data for the corresponding periods in terms of: 1) water allocation; 2) precipitation; 3) evaporation; 4) commodity prices for lamb, mutton, wool, cattle, wheat, feeding barley, butter, milk powder and cheese; 4) interest rate; 5) exchange rate (US\$); 6) trade weighted index; 7) inflation indexes; 8) index of rural commodity prices; and, 9) GDP figures for the farm sector, the non-farm sector and per capita. During the early years of the period, trade in the temporary water market was limited, resulting in low numbers of observed temporary prices. Over this period, the market matured considerably and irrigators widely adopted the use of temporary markets (Bjornlund, 2003b), resulting in a larger and more consistent set of observed prices.

Market activities within the temporary water market has increased during the study period, but in seven out of the 10 years, more than $10 \%$ of all water entitlements were traded and the proportion of all water use generated by trade has varied from around $4 \%$ during years with 'normal' supply and up to $24 \%$ during the years with the highest level of scarcity (Bjornlund, 2004).

These data have been used for the analysis in the following three sections. The water and commodity prices used for the correlation analysis and hedonic functions 
have been adjusted for inflation using the CPI inflation index, while the time series analyses are based on nominal real time prices.

\section{The application of correlation analyses}

Table 1 gives the Pearson correlations and their significance levels between temporary market prices adjusted for inflation and the expected drivers of these prices. The variables are measured in real time with the exception of rainfall, which are lagged for 1, 2 and 3 periods because correlation coefficients became significant when lagged.

Table 1: Correlations between water prices and drivers: July 1993 to June 2003

\begin{tabular}{|c|c|c|c|c|c|c|c|}
\hline $\begin{array}{l}\text { Climate, supply and } \\
\text { market }\end{array}$ & Correlation & $\begin{array}{c}\text { Commodity } \\
\text { prices }\end{array}$ & Correlatic & tion & $\begin{array}{l}\text { Macro economic } \\
\text { variables }\end{array}$ & Correlati & ion \\
\hline Allocation level & $-0.61 *$ & Lamb & 0.30 & $* 1$ & Interest rate & -0.46 & $*$ \\
\hline Rainfall Kyabram & -0.16 & Mutton & 0.36 & $* 1$ & Exchange rate US\$ & -0.39 & $*$ \\
\hline Rainfall Kyabram lag 1 & $-0.24 * *$ & Cattle & $-0.29 *$ & * & Trade weighted index & -0.12 & \\
\hline Rainfall Kyabram lag 2 & $-0.21 * *$ & Wool & 0.10 & & GDP per capita & 0.57 & $*$ \\
\hline Rainfall Kyabram lag 3 & $-0.26 * *$ & $\begin{array}{l}\text { Wheat } \\
\text { Feeding }\end{array}$ & -0.39 & $*$ & CPI Index base 1990 & 0.52 & $*$ \\
\hline Evaporation Kyabram & 0.12 & barley & 0.12 & & CPI inflation index & 0.63 & $*$ \\
\hline Volume Traded & $0.26 * *$ & Butter & -0.44 & $*$ & GDP farm sector & -0.03 & \\
\hline Number of Transfers & $0.42 *$ & Cheese & -0.67 & $*$ & GDP non-farm sector & 0.61 & $*$ \\
\hline $\begin{array}{l}\text { Permanent Market } \\
\text { Water Price }\end{array}$ & $0.54 *$ & $\begin{array}{l}\text { Skim milk } \\
\text { power }\end{array}$ & -0.57 & $*$ & $\begin{array}{l}\text { Index rural } \\
\text { commodity prices }\end{array}$ & 0.47 & $*$ \\
\hline
\end{tabular}

Insignificant commodity variables remained insignificant when lagged by 1, 2 and 3 months. The significant commodity variables remained significant when lagged; however, they changed their significance level. Lamb and wheat reduced their correlation coefficient with each lag, but retained their sign (lamb down to $r=0.17$ and wheat to $r=-0.38$ at lag 3 ), while cattle, mutton and dairy products retained their sign and increased their correlation coefficient (cattle to $r=-0.31$, mutton to $r=0.4$, butter to $r=-0.50$, skim milk to $r=-0.65$, and cheese to $r=-0.70$ at lag $3)$.

Insignificant macro-economic variables remained insignificant when lagged. The correlation coefficient for interest rate goes up slightly at lag one, but ends up at the same correlation at lag 3. Exchange rate, rural commodity index and the CPI 
inflation index have an increased correlation coefficient with increased lag, while non-farm sector GDP and GDP per capita have a declining correlation coefficient. All significant variables remained significant at the 0.01 level.

\section{Climate, supply and market}

A number of important observations can be made from Table 1. Prices in the temporary market are significantly correlated with the activity in the market, both in terms of the number of transfers and the volume traded; the higher the level of market activity, the higher the price, with the number of transfers being more significant than the volume traded. It seems that the higher the volume of water traded in the market, the higher the scarcity and therefore the higher the price. In response to higher prices, irrigators seem to buy less water more frequently, to accommodate their cash flow and to see if it should rain or if the allocation should be increased, which would make further purchases unnecessary. There is also a significant relationship between prices paid in the temporary and the permanent markets. This is supported by anecdotal evidence in the market. When temporary water was cheap and easily available, irrigators relied heavily on temporary purchases; as temporary prices and water scarcity increased, it became increasingly uncertain to secure the necessary water at a reasonable price. Irrigators therefore became impatient with the temporary market and started to buy more water in the permanent market, and by so doing, increased demand and prices in that market. Also, in an economically efficient market, the two prices should move in unison with permanent prices reflecting the capitalized value of the temporary price at a market discount rate.

There is an insignificant, but logical relationship between price and precipitation and evaporation, suggesting that prices decrease as rain increases and increase as evaporation increases. However, the precipitation variable becomes significant at the 0.05 level if lagged 1 to 3 months showing that prices drop as precipitation increases.

\section{Commodity prices}

Correlations with commodity prices are predominantly significant at the 0.01 level and correlations increase with lagged variables, suggesting that farmers' willingness to pay is influenced by commodity prices over the past three months prior to the month in which the transaction takes place. The signs of the correlation coefficients are however not entirely logical. The correlations between lamb, mutton, wool and feeding barley are positive, indicating that higher commodity prices result in higher water prices, which could have been hypothesized. These farmers are the low value producers in the region and therefore good commodity prices for them increases the price at which they are willing to sell their water rather than produce their commodities. The coefficients for wheat and cattle however are negative, suggesting that water prices increase as commodity prices decrease; this could be caused by the fact that most of these farmers are mixed farmers. They may therefore react to the price of the commodities with a positive coefficient. All dairy products 
are highly significant but with a negative sign; again this suggests that dairy farmers' willingness to pay increases as the value of their commodities decreases. Theoretically, this does not make sense but has a logical explanation; the willingness of dairy farmers to pay is not driven by maximizing their output due to high commodity prices, but rather by their desire to maintain their herd and production during a period with scarce supply. Over the ten-year period, prices for dairy products have generally been drifting downward, while water prices have increased. However, due to the significant capital investment in milking herd, milking equipment and permanent pastures, as well as a relatively high gross margin per ML of water used, dairy farmers have been willing to pay increased prices for water, even if that has resulted in a reduced net profit per ML of water applied.

\section{Macro-economic indicators}

Price has a significant and negative correlation with interest rate and the exchange rate between the A\$ and the US\$. As interest rates increase, farmers' willingness to pay for water decreases, which is consistent with economic theory. However, the time series is not long enough to establish this relationship properly. Prices were low in the early nineties, when the market was young and allocations and interest rates high, while prices were high toward the end of the period when the general interest level and allocations were low. The correlation with US\$ is also negative, suggesting that a lower exchange rate results in higher prices; this makes economic sense, since a low exchange rate improves the terms of trade for the agricultural sector, which predominantly is export driven and paid in US\$.

The correlation with the index of rural commodities is significant and positive. This suggests that the more rural commodities in general increase in price, the higher the willingness to pay. Given our findings discussed under commodity prices above, this could be a surprise since many of the commodities tested there were negative, but could be an indication that it is other commodities, than those predominantly grown in the study region that drives prices, such as vegetables, horticultural commodities and wine grapes. Some of these commodities are grown in pockets within the study region, but are more predominantly grown downstream. However, trade can take place from the study region to these downstream regions with higher valued productions.

The correlation with the CPI inflation index is significant and positive; this indicates that the increase in water prices has been well above inflation, since the prices used for the analysis already have been adjusted for inflation. Finally, there is a significant and positive correlation with GDP for the non-farm sector and GDP per capita, while there is an insignificant correlation with farm sector GDP. This again suggests that water prices have not been driven up by a growth in the gross domestic product in the farm sector, since this sector has had a hard time during the last six of the ten years included in this study period. It also emphasizes that 
scarcity in supply due to the drought has forced high value producers with permanent plantings and pastures to pay higher and higher prices, not in pursuit of higher commodity prices, but in an effort to remain in business during a period of drought. That the correlation is positive and significant with general and non-farm sector GDP simply reflects the fact that the period has seen general GDP growth in the society, despite a stagnating period in the rural sector, and that farming households in the study region have a significant level of dependence on off-farm work (Bjornlund, 2002c).

\section{The application of hedonic functions}

Method and model discussion

Hedonic functions were next applied to water prices in order to determine which of the identified price determinants had a significant impact on irrigators' willingness to pay for water and quantify that impact. In the first instance, analyses were carried out with price as the dependent variable. This resulted in a relatively high $\mathrm{R}^{2}$ value of 0.75 , with cattle, wool and wheat prices together with the allocation level, evaporation figures, and interest rates comprising the independent variables. However, as expected, there was strong multicollinearity between a number of the independent variables; this was particularly prominent between many of the commodity prices and most of the macro-economic variables; furthermore, the Durbin-Watson statistics showed strong signs of positive serial correlation due to the time series nature of all variables.

Table 2: Hedonic function for temporary water market prices: $1993-\mathbf{2 0 0 3}^{1}$

\begin{tabular}{lcccc}
\hline Adjusted $\mathrm{R}^{2}$ & 0.522 & & & \\
$\mathrm{~F}$ & 10.971 & & Significance level & 0.000 \\
\hline Variable & Coefficient & $\mathrm{t}$ & Significance level & VIF \\
\hline Wool prices & 0.211 & 3.01 & 0.004 & 1.438 \\
Cattle prices & -0.843 & 4.16 & 0.000 & 1.304 \\
Feeding barley prices lagged 1 month & 0.457 & 2.49 & 0.015 & 1.147 \\
Index of rural commodity prices & 2.053 & 3.37 & 0.001 & 1.458 \\
Allocation level & -1.001 & 3.98 & 0.000 & 1.223 \\
Evaporation measured at Kyabram & 0.092 & 3.48 & 0.001 & 1.195 \\
GDP non-farm sector & 0.005 & 2.43 & 0.018 & 1.193 \\
Interest level & -18.499 & 2.01 & 0.049 & 1.121 \\
Constant & -2.561 & 1.34 & 0.185 & \\
\hline Dependent variable is the change in mean monthly prices paid in the temporary market. All prices both \\
$\begin{array}{l}\text { as dependent variables and independent variables are adjusted for inflation back to July 1993 prices. All } \\
\text { variables are first differences indicating the change in the variable since the last data point. }\end{array}$ \\
\hline
\end{tabular}


First differences were therefore applied to both dependent and independent variables to eliminate the problems with serial correlation, and individual variables were selected as proxies for commodity prices and macro economic variables to overcome multicollinearity problems. Lagged variables were also tested, as it would make economic sense that irrigators have a delayed reaction to changes in the underlying factors affecting their willingness to pay. However, in most instances, the real time variables were the most significant. Seasonal dummy variables were also tested, since classical decomposition techniques showed strong seasonal variation. However, as could have been expected, there are very strong levels of multicollinearity between these seasonal dummy variables and evaporation levels. It was decided to keep the evaporation variables in the model since that makes more conceptual sense. The final model is shown in Table 2. It has an adjusted $\mathrm{R}^{2}$ of 0.522 , which is a very acceptable level for models using first differences, and an F value of 10.971 indicating a significant model; the Durbin-Watson statistics of 2.469 shows that the model is free from serious autocorrelation; a maximum VIF figure of 1.458 and a maximum condition index of 2.416 prove that there is no indication of multicollinearity in the model; finally, most variables are significant at the 0.01 level.

Commodity prices

Commodities are represented in the model by three variables and the composite index of rural commodities. Firstly, we discuss the commodity variables included in the model: (i) water prices are positively influenced by wool prices, and correlation analysis shows that wool prices are significantly and highly correlated with prices of wheat, barley and dairy products. However, while wool and barley have a positive correlation with temporary prices, wheat and dairy prices have a significantly strong negative correlation (see Table 1). This indicates that high prices of lower valued commodities, such as wool and barley, decreases the willingness of these farmers to sell, which again raises the price at which they are willing to sell their water; (ii) water prices are negatively influenced by cattle prices; this probably reflects the fact that cattle farmers have not been price setters and that most larger cattle farmers are mixed grazing and cropping farmers trading in the water they normally use for wool or cropping rather than for cattle production. This to some extent also corresponds with findings by Bjornlund (2002c) that a large proportion of cattle farmers are smaller life style farmers; (iii) water prices are positively influenced by the price of feeding barley lagged one month. This is likely to be caused by dairy farmers, since higher feed prices increases dairy farmers willingness to pay for water to grow grass rather than buy feed; the hedonic function suggests that dairy farmers willingness to pay for water increases by 45.7 cents for each dollar feeding barley increases in price per ton; and iv) water prices are positively influenced by a composite rural commodities index. This reflects the impact of other high value commodities grown within the area, as well as outside the area, such as vegetables and horticulture. This also corresponds with previous findings that the price of wine grapes has been the main driver of 
interstate trade and prices during the first two years of the pilot program (Young et al., 2000). Due to problems associated with obtaining consistent data related to these commodity prices on a monthly basis, it has not been possible to include them in the model, but the composite index is a good proxy for the influence of these commodities.

Since dairy farming is the predominant high value user and the biggest buyer in the area, it is interesting to note that dairy prices are strongly negatively correlated with water prices and that in the first difference model, dairy prices fail to be significant. Combined with the fact that feeding grain is positively related to price, this emphasizes the findings that dairy farmers have been buying and paying in response to the cost of alternative feed to grass, in addition to the potential losses and costs associated with not providing enough feed.

\section{Supply factors}

The allocation measures the level of supply and indicates that prices decrease by one dollar for each percent the allocation level increases. This is as expected, since at high allocations, many irrigators do not need to buy extra water, which reduces demand and therefore price in the market. The allocation also reflects the level of natural precipitation in the catchment rather than within the local area, and also reflects the level of precipitation during the last winter seasons rather than the precipitation in real time. The evaporation factor on the other hand reflects the climatic conditions in the local area and affect demand in real time. If evaporation is high, the need for irrigation is also high in order to not only supply the plants with the water they need, but also to replace what evaporates. The coefficient for evaporation is therefore positive, suggesting that the increased need for irrigation increases demand and therefore farmers' willingness to pay by 9.2 cents a ML per $\mathrm{mm}$ of evaporation during the month.

\section{Macro-economic factors}

The final two variables in the model measure the impact of macro-economic factors. The coefficient for non-farm sector GDP is positive, which suggests that water prices adjusted for general inflation increases as the general wealth in the non-farm sector of the society increases, which should be expected. Finally, the coefficient for the interest level is negative, suggesting that the price of water goes down by $\$ 18.50$ per ML for each one percent the interest level goes up, which is in accordance with general economic theory.

\section{The application of time series analysis}

\section{Methods and model discussion}

Given the main findings in the preceding two sections that water prices are most significantly driven by water scarcity and that prices have increased well in excess of general inflation in the economy, basic time series analyses were applied to the data set of nominal real time prices to further investigate these two issues and to 
enable the series to be described in terms of trend, seasonality and cycle. Simple time series decomposition is used in a multiplicative form. A regression model in an exponential form using a time index and seasonal dummy variables is used to estimate seasonal indices and a compounding growth rate (trend). The ratio to moving average approach is also used to estimate seasonal indices through the ratio of observed values to a 12 period-centered moving average. This 12-period centered moving average is then used to estimate the trend via a simple time index regression in exponential form. The advantage of the regression approach is that it enables confidence intervals to be estimated for the seasonal indices while the ratio to moving average method does not. For both models, the cycle component is estimated as a ratio of the de-trended and de-seasonalised data to the observed data. The patterns in the cycles are then examined for relationships with causal factors.

Table 3: Time index regression model using seasonal dummies for temporary water market prices: 1993-2003

\begin{tabular}{lcccc}
\hline R Square & 0.656325 & & & \\
$\mathrm{~F}$ & 17.02842 & & Significance level & 0.0000 \\
\hline Variable & Coefficients & $\mathrm{t}$ & Significance level & Exp (bn) \\
\hline Constant & 2.3748 & 10.3563 & 0.0000 & 10.7488 \\
Time Index & 0.0232 & 13.5181 & 0.0000 & 1.0235 \\
Jan & 0.0715 & 0.2469 & 0.8055 & 1.0742 \\
Feb & -0.0739 & -0.2552 & 0.7991 & 0.9287 \\
Mar & -0.2059 & -0.7104 & 0.4790 & 0.8139 \\
Apr & -0.3644 & -1.2572 & 0.2114 & 0.6946 \\
May & -0.6658 & -2.2966 & 0.0236 & 0.5139 \\
Jun & -0.6890 & -2.3761 & 0.0193 & 0.5021 \\
Jul & -0.6868 & -2.3692 & 0.0196 & 0.5032 \\
Aug & -0.1025 & -0.3536 & 0.7243 & 0.9026 \\
Sep & -0.0267 & -0.0922 & 0.9267 & 0.9736 \\
Oct & 0.1212 & 0.4184 & 0.6765 & 1.1289 \\
Nov & 0.0397 & 0.1368 & 0.8914 & 1.0404 \\
\hline $\begin{array}{l}\text { Dependent variable is the natural log of price. Coefficients are in natural log form and are } \\
\text { converted using the exponent in the last column. }\end{array}$ & No dummy variable is recorded for \\
December that becomes the base quarter for comparison, hence the coefficient for December \\
is 0 and the exponent is 1.
\end{tabular}

The results for the regression approach are shown in Table 3. The $\mathrm{R}^{2}$ of .65 and $\mathrm{F}$ value of 17.028 indicate a significant overall model. The $t$ statistics show that the constant and time index variables are significant, but that only the May, June and July seasons are significantly different to zero. Hence, we are not even $80 \%$ 
confident that any of the other months varies from the December figure. The exponent of the coefficients is used to convert the values from the log form and these are then normalized so that the seasonal indices sum to 12 . These final seasonal indices are indicated in Table 4.

Table 4: Calculated Seasonal Indices for temporary water market prices: 1993-2003

\begin{tabular}{lcc}
\hline & \multicolumn{2}{c}{ Seasonal Index } \\
\cline { 2 - 3 } Month & Regression & Ratio to Moving Average \\
\hline January & 1.28 & 1.24 \\
February & 1.11 & 1.06 \\
March & 0.97 & 0.95 \\
April & 0.83 & 0.81 \\
May & $0.61 * *$ & 0.63 \\
June & $0.60 * *$ & 0.60 \\
July & $0.60 * *$ & 0.58 \\
August & 1.07 & 1.13 \\
September & 1.16 & 1.21 \\
October & 1.34 & 1.34 \\
November & 1.24 & 1.23 \\
December & 1.19 & 1.20 \\
$*$ denotes significance at the 0.01 level & \\
** denotes significance at the 0.05 level & \\
\hline
\end{tabular}

Analyses of seasonality and trend

It is expected that the series will show strong seasonal characteristics consistent with the changes in rainfall, together with a compounding growth and significant cyclical activity that should be related to similar drivers as in the hedonic models.

The seasonal indices from both methods are very similar, but only those for May, June and July are significant, indicating that the other seasonal indices are not consistent. Since the seasonal fluctuations are related to the seasonal effects of rain and evaporation, the prices paid will fluctuate more with rainfall than with a fixed (monthly) seasonal effect. Only in May to July, when rainfall is reasonably consistently high and trading is limited, is there a statistically significant seasonal effect. This supports the results from the hedonic models and suggests that the prices are a function of actual rainfall not "expected" rainfall. If the later was the cause of price fluctuation and not the actual rainfall, then we would expect all seasonal indices to be significant and a better indicator than the actual rainfall. 
The seasonal indices can be interpreted in percentage terms. A value of 1 represents no seasonal effect, with that period having the yearly average. The temporary water prices in May to July are only about $60 \%$ of the yearly average (seasonal index of .6). The March price is about average for the year. Prices in August through to February are above the yearly average, with peak prices in October at around $34 \%$ above the yearly average.

In the previous regression model (Table 3), the seasonal and trend components are both estimated simultaneously. Using the classical decomposition model, the data are first deseasonalised and then the trend component is estimated using a simple regression equation. The results for this regression are shown as Table 5. The results for this are quite consistent with the same parameters in the former regression estimate (Table 4). The functional form of the exponential model means that the exponent of the index variable can be interpreted as a growth rate. Using the results from Table 5, this exponent is 1.0227 implying a monthly growth rate of $2.27 \%$ or an annualised rate of $30.85 \%$. This shows the dramatic underlying trend in the growth of temporary water prices as the market matures. While this growth has been experienced over the period of the data, it is not anticipated that this trend will continue as the region comes out of the recent drought; in the long term, it is expected that growth will more closely follow the growth in the overall economy.

Table 5: Simple exponential regression for time index and 12 period CMA for temporary water market prices: 1993-2003

\begin{tabular}{lcccc}
\hline R Square & 0.688746 & & & \\
$\mathrm{~F}$ & 234.5575 & & Significance level & 0.0000 \\
\hline Variable & Coefficients & $\mathrm{t}$ & Significance level & Exp (bn) \\
\hline Intercept & 2.2711 & 22.8054 & 0.0000 & 9.6902 \\
Time Index & 0.0224 & 15.3153 & 0.0000 & 1.0227 \\
\hline
\end{tabular}

Analysis of cycle ratio

Figure 1 shows the actual prices, the deseasonalised (CMA) and the trend component. The ratio between the CMA and trend lines is the cycle ratio and this can be used to analyze the longer-term cycles. These cycles are notoriously difficult to estimate (in some markets they are quite random) and the difficultly generally lies in predicting the turning points, when the cycle moves from expansion to contraction and visa versa. As already stated, it is expected that the longer-term fluctuations in prices are likely to be related to fluctuations in rainfall. However, since it is a longer-term fluctuation, it should be related to longer run rainfall variations such as a yearly average. The cycles in prices might then be related to a lagged cycle in rainfall. The rainfall figures are deseasonalised using a 12-period moving average as for the prices. The long-term deseasonalised average 
rainfall is expected to be stationary series. In the absence of trend and seasonality, any pattern represents a "cycle" in rainfall. The rainfall and prices cycles are shown in Figure 2.

Figure 1: Ratio to moving average components temporary water market prices: 1993-2003

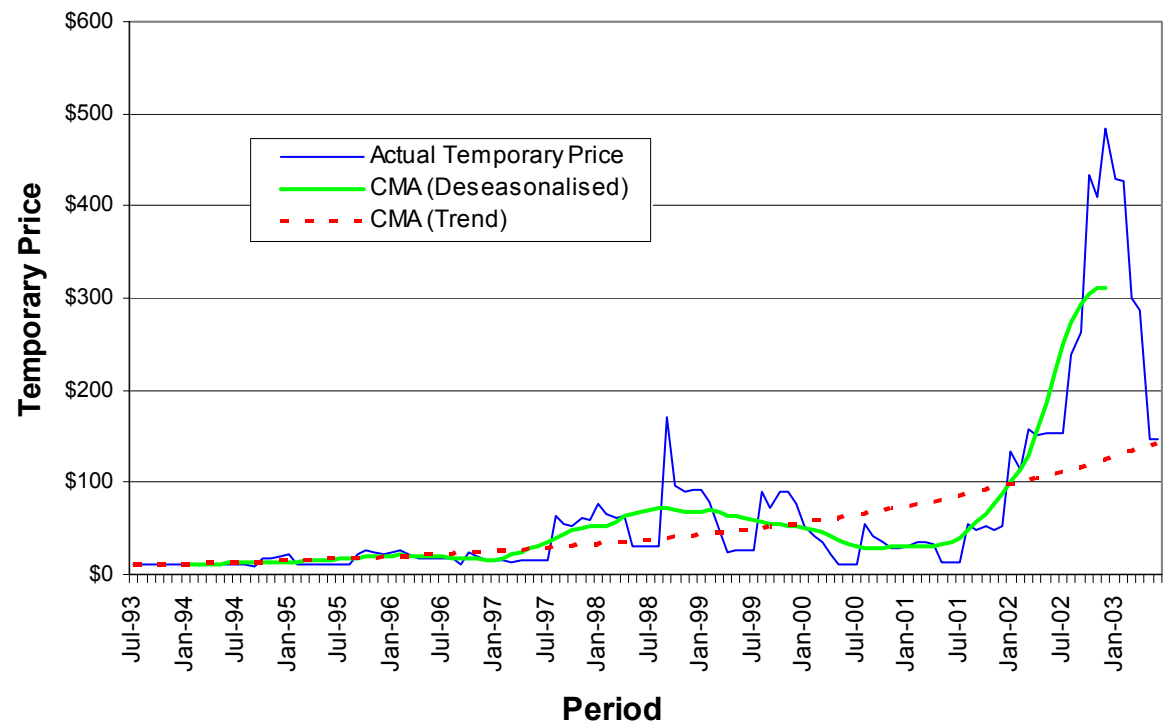

The chart shows the strong negative relationship between the prices paid and the lagged moving average rainfall. This corresponds to a correlation coefficient of -.68. The rainfall cycle clearly shows the drought periods in the 1995, 1997-1998 and then the longer drought from 2001 through 2003. In response to these periods, the prices have risen above the long-term trend and expected seasonal figures, creating the peak in the temporary prices. Price cycled downwards towards a trough when rainfall was good such as during 1996 and 2000. A simple regression is used to predict the cycle ratio from the lagged rainfall CMA. 
Figure 2: Cycle ratios, temporary water price and rainfall lagged 6 months

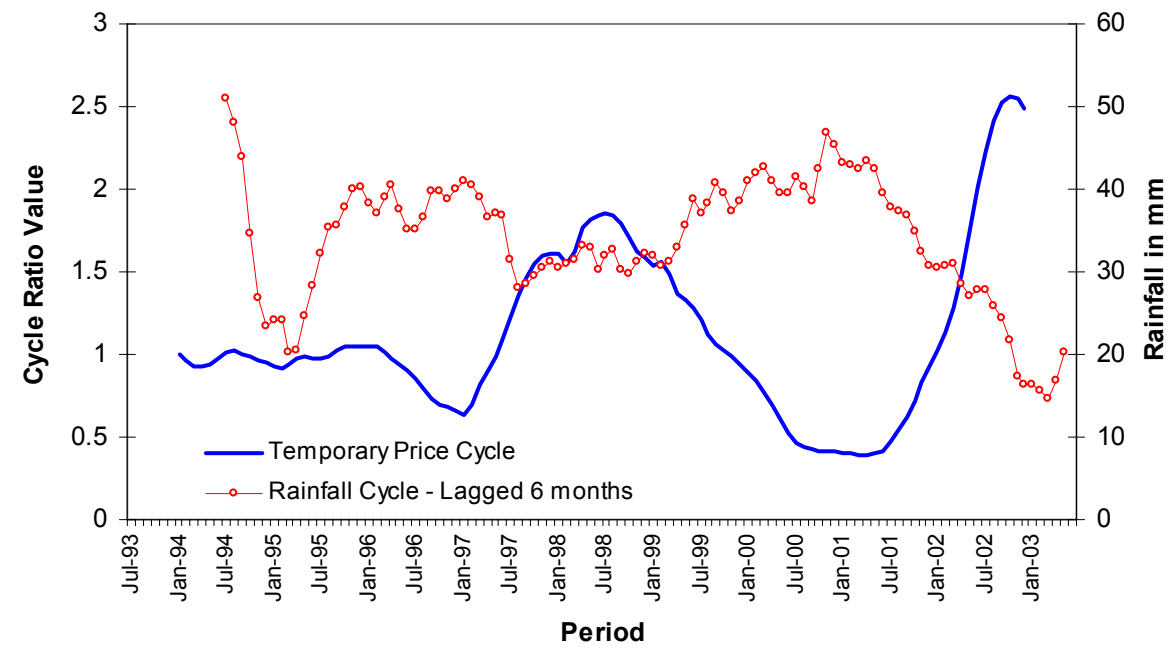

To test the overall validity of the ratio to moving average model, a forecast is made and compared to the actual data. This forecast is based on the exponential trend, seasonal factors and cycle ratios estimated from the lagged rainfall cycle. The forecast and actual prices are shown in Figure 3.

Figure 3: Actual and predicted values, temporary water market prices: 19932003

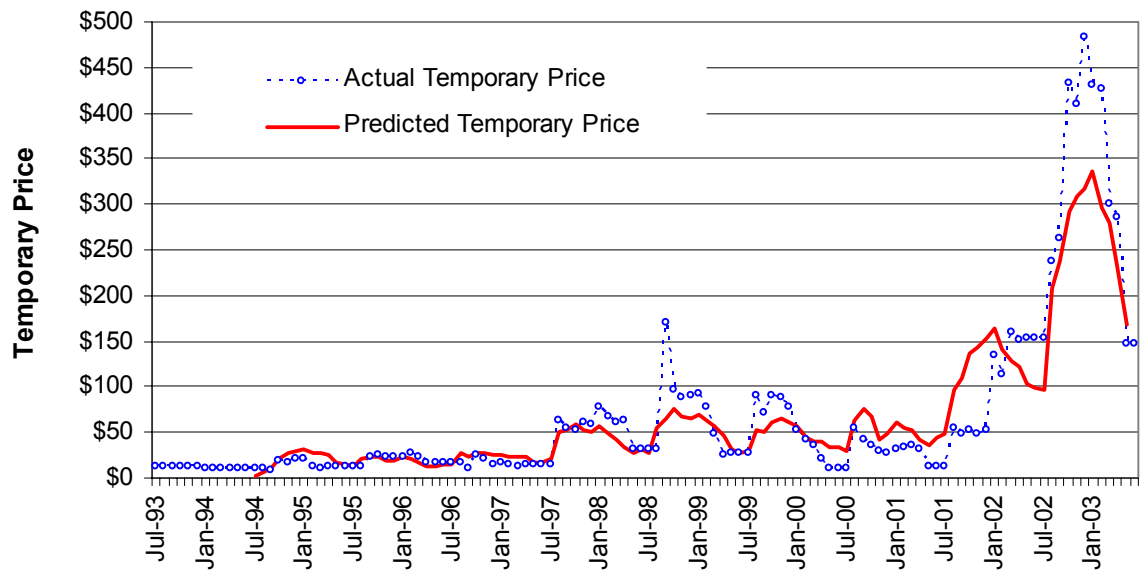

Period 
The model produces a good estimate for temporary prices. It clearly captures the long-term trend, but has some over and under estimation in the seasonal factors. Much of this is likely to be related to the wider macro economic issues not captured in this model. Although the model does not acutely predict the amplitude of each peak and trough, it does quite accurately estimate the turning points. The estimation of the turning points in the 2002-2003 cycles is particularly impressive.

\section{CONCLUSIONS AND RECOMMENDATIONS}

This paper analyses prices paid in the temporary water market within the Goulburn Murray Irrigation District in Victoria, Australia in order to identify the factors determining the willingness of irrigators to pay for water. Correlation, regression and time series techniques have been applied to water market prices and factors hypothesized to influence farmers' willingness to pay and accept prices in the temporary water market. Economic theory suggests that the following factors should be important: (i) commodity prices; irrigators should be willing to pay a higher price for water, or only be willing to sell at higher prices, when the prices of the commodities they are growing are high; (ii) supply and demand; irrigators should be willing to pay more when supply is scarce, that is when allocations are low and when demand is high, which is during periods of drought and high levels of evaporation; and (iii) macro economic indicators such as interest rates, foreign exchange rates and GDP growth; irrigators should be willing to pay a higher price during periods with low interest rates, low exchange rate and high GDP growth.

The analysis suggests that the above factors have all had an impact on the willingness of irrigators to pay for water during the ten-year period. However, commodity prices have had a limited impact, which has not always been consistent with economic theory. In the hedonic function and the correlation analyses, many commodities have a negative coefficient, suggesting that farmers are willing to pay a higher price for water when they receive lower commodity prices. This is inconsistent with economic theory, but consistent with developments within the study region over the ten-year period. Most of the period has been dominated by drought conditions and the region has therefore experienced severe levels of water scarcity and very high levels of demand. All the analyses conducted for this paper suggest that the most important drivers of farmers' willingness to pay for water are water supply and demand represented by the level of seasonal allocations as well as precipitation and evaporation. High value farmers with investments in long-term plantings, pastures and equipment are forced to pay high prices during periods of scarcity to limit their potential losses caused by drought. During periods of scarcity, there is little opportunistic buying by irrigators trying to benefit from high commodity prices, since the price of water during such periods is far in excess of what can be made on any annual crops and also on dairy production, even when prices for these commodities are very good. This is likely to change during periods of normal or plentiful supply when the protective high value buyers leave the 
market and prices therefore return to levels reflecting water's productive value. Finally, both interest rates and exchange rates with the US dollar have a significant negative impact on price, with lower rates resulting in higher willingness to pay; this is in accordance with economic theory. Price is positively related to GDP growth in the non-farming sector, but not with growth in the farming sector. This further highlights the fact that farmers have paid high prices not due to economic growth in their sector, but rather to protect their production during a period of water scarcity and therefore very low economic growth within the sector.

Due to the pressure of water scarcity, water prices have increased with an implied growth of more than $30 \%$ per annum, well above general inflation. This exponential growth is also likely to stop once supply normalizes. While the findings from this research are significant and important, it is essential that the analysis be repeated when a longer time period is available, which includes periods of normal and plentiful supply.

\section{Acknowledgements}

This research project is funded by the Australian Research Council and ten industry partners: Dep. of Water Land and Biodiversity Conservation, Dep. of Primary Industries, SA-Water, Central Irrigation Trust and River Murray Catchment Water Management Board in South Australia, Goulburn-Murray Water, and Dep. of Natural Resources and Environment in Victoria, Murray Irrigation Limited, and Dep. of Land and Water Conservation in NSW, and the Australian National Committee on Irrigation and Drainage.

\section{REFERENCES}

Adamowicz, W.L. and Horbulyk, T.M. (1996). The role of economic instruments to resolve water quality problems. Canadian Journal of Agricultural Economics 44, 337-344.

Bjornlund, H. (2004). Formal and informal water markets: drivers of sustainable rural communities? Water Resources Research 40, in print.

Bjornlund, H. (2003a). Farmer participation in markets for temporary and permanent water in south-eastern Australia. Agricultural Water Management 63(1), $57-76$.

Bjornlund, H. (2003b). Efficient water market mechanisms to cope with water scarcity. Water Resources Development 19(4), 553-567.

Bjornlund, H. (2003c). What is driving activities in water markets. Water 30(7), 3036 . 
Bjornlund, H. (2002a). Signs of maturity in Australian water markets. New Zealand Property Journal, July, 31-46.

Bjornlund, H. (2002b). What impedes water markets. Proceedings from the $4^{\text {th }}$ Australasian Water Law and Policy Conference, Sydney, 24-25 October, 165-176.

Bjornlund, H. (2002c). The socio-economic structure of irrigation communities water markets and the structural adjustment process. Journal of Rural Society 12(2), 123-145.

Bjornlund, H. and McKay, J. (2000). Are water markets achieving a more sustainable water use? Proceedings from the $X$ World Water Congress, Melbourne, March, CD-Rom.

Colby, B.G., Crandall, C. and Bush, D. (1993). Water right transactions: market values and price dispersion. Water Resources Research 29(6), 1565-1572.

DNRE, Department of Natural Resources and Environment. (2001). The Value of Water - A Guide to Water Trading in Victoria. Melbourne: DNRE.

Kerr, S., Newell, R.G. and Sanchirico, J.N. (2003). Evaluating the New Zealand Individual_Transferable Quota Market for Fisheries Management. Paper prepared for a workshop on ex-post tradable permit evaluation for the National Policies Division, Environment Directorate. Paris: OECD.

Person, P. and Michelsen, A. (1994). Determinants and Trends in Water Right Prices: An Econometric Analysis. Wyoming Water Resources Centre, Laramie, Wyoming.

Young, M., Hatton-McDonald, D., Stringer, R. and Bjornlund, H. (2000). InterState Water Trading: A Two-Year Review, CSIRO Land and Water, Adelaide. 